\title{
Living on the Ring of Fire: Perspectives on Managing Natural Hazard Risk in Pacific Rim Countries
}

\author{
Douglas Paton \\ University of Tasmania, Australia
}

\begin{abstract}
Erom the perspective of studying natural hazards, the peace and tranquillity that might be expected - from a literal translation of its name does not always capture the reality of life for communities on the Pacific Rim. This reality is more readily discerned in its alter ego: the Ring of Fire. The latter leaves one in less doubt as to the hazardous circumstances likely to prevail in this region. In addition to the hazards posed by the numerous volcanoes that resulted in the 'Ring of Fire' appellation, communities situated around the Pacific Rim also have to contend with earthquakes, tsunami, storms, cyclones/typhoons, flood and bushfire. To this list of acute events can be added hazards of a chronic nature such as salinity, environmental degradation and sea-level rise that represent growing threats to many Pacific Rim countries. The region also faces increased risk from health-related hazards. Sydney, for example, has been identified as a pandemic hotspot as a result of it being a hub linking the airways of Asia and the United States.
\end{abstract}

Recognition of the risk these hazards pose to Pacific Rim communities has stimulated interest in identifying how to facilitate sustainability by developing community and societal capacity to co-exist with the potentially hazardous elements in the environment (Paton, 2006a). It is by developing a capacity for co-existing with periodically hazardous environmental processes that a community can more readily adapt to and recover from the disruptive consequences of hazard activity. The contents of this special edition offer insights into how achievement of the goal of developing adaptive capacity and sustainability might be advanced. These insights accommodate both the complex interrelationships and cultural diversity characteristic of communities around the Pacific Rim and the multi-hazard nature of the environment in which people in Pacific Rim countries live and work.

Because disaster impacts on people, communities and societal functions and institutions, a comprehensive representation of adaptive capacity must accommodate multiple levels of analysis. When examining complex socio-environmental processes, however, psychology has often fallen foul of the context minimisation error and failed to adequately address how the social context in which people live influences people's thoughts and actions (Joffe, 2003). The articles presented here accom- modate this issue and offer insights into how personal, community, societal, cultural and organizational factors interact to facilitate sustainability. Furthermore, they do so in a way that supports the growing recognition of a need to integrate risk management strategies within mainstream community activities (Paton, 2000; 2009).

The articles that comprise the special edition cover volcanic, earthquake, flood, heatwave and tsunami hazards. To provide as representative a picture of hazard research within Pacific Rim countries as possible, the collected papers draw on work conducted in New Zealand, Australia, Taiwan, Indonesia, Japan, India and the United States. The special edition is presented in two parts.

Part 1 opens with Cottrell's account of how women have developed strategies to adapt to an annual hazard, the wet season in northern Australia. Cottrell highlights the need to distinguish between resilience and vulnerability, and demonstrates the consequent benefit that can accrue to our understanding of adaptive capacity from so doing. Cottrell's study illustrates the insight and ingenuity that the woman she studied brought to the process of facilitating their ability to adapt to uncertain and threatening circumstances.

In the next article the focus switches from demographic to dispositional influences on hazard

Address for correspondence: Douglas Paton, School of Psychology, University of Tasmania, Launceston TAS 7250, Australia. E-mail: Douglas.Paton@utas.edu.au 
preparedness. Mishra et al. discuss preparedness for flood and heatwaves. They discuss how prior experience of hazard consequences interacts with the dispositional characteristic of locus of control to predict preparedness for these hazards. In their respective discussions, both Cottrell and Mishra et al. allude to the fact that understanding what people do to protect themselves from hazard consequences cannot be fully accomplished without including a social dimension in the analysis.

The importance of including a social dimension in the process of understanding adaptive capacity derives from the fact that people's preparedness choices result from judgments made about risk and what to do about it in the context of their interactions with others. Community interaction thus plays a pivotal role in developing and sustaining the meanings that people attribute to events as well as how they decide to respond to events.

In the next article, de Terte et al. pick up this theme and examine how a model traditionally used to inform cognitive behavioural therapy, the Five Part or Five Areas Model, can be adapted to provide a framework for identifying the person, family and community interdependencies that need to be accommodated when conceptualising resilience. The influence of social contexts on hazard preparedness is continued in the final article in Part One of this special edition.

Paton et al. explore how a model that examines how personal beliefs, community characteristics and competencies and the quality of the relationship between communities and civic agencies interact to influence the adoption of preparedness measures for tsunami hazards. An important aspect of this work lies in it providing an empirical demonstration of how the cumulative experience and interpretation of everyday community and societal life influences how people manage the risk posed by natural hazards.

Part 2 of this special edition continues the exploration of the role of community processes in facilitating people's capacity to adapt to hazard consequences. It also addresses all-hazards issues and includes papers that address how cultural factors, at both national and organisational levels, influence adaptive capacity.

The model introduced by Paton et al. in the final article in Part 1 of this special edition was originally developed to provide emergency planners with an evidence-based framework for developing the public outreach component of risk management strategies. The confidence that this sector can have in such a model can be enhanced by their knowing that it can inform their risk management planning independently of any specific hazard. The importance of the latter derives from the fact that the Pacific Rim communities generally have to contend with several hazards. A model with restricted applicability would have limited value.

The challenge of examining the all-hazards capability of the model introduced in the Paton et al. article is picked up by McIvor et al. In addition to demonstrating support for the predictive utility of the model for earthquake and flooding hazards in New Zealand and Australia, respectively, McIvor et al. offer some suggestions on how the model might profitably be developed. The demonstration of an all hazards capability is not the only hurdle that any explanatory model intended for use in Pacific Rim countries must negotiate. Another derives from a need to accommodate the cultural diversity characteristic of Pacific Rim communities and the need for risk management strategies to be applied in multicultural cities, such as Auckland and Sydney.

The question of whether the model can be applied in a country whose cultural characteristics differs substantially from those in New Zealand and Australia is addressed by Sagala et al. They discuss the ability of the model described in the Paton et al. article to account the differences in intention to prepare for volcanic hazards in communities around the Mt. Merapi volcano in Indonesia. Furthermore, by drawing on comparative evidence from New Zealand and Japan, they present evidence to support the multicultural applicability of the model. A demonstration of some cross-cultural equivalence in how people confront natural hazard risk does not mean that research into culture-specific processes should be neglected.

In their article, Jang and Wang's investigation of the Hakka people residing in Taiwan illustrates how a culturally specific mechanism can influence adaptive capacity. They discuss how aspects of community life derived from mainstream farming practices combined with a belief that people should co-exist with nature influenced the development of their ability to respond to a destructive earthquake in a way that was both adaptive and that led to social growth.

While the issues introduced in the preceding articles will play important roles in facilitating people's capacity to adapt to and recover from hazard events, the sheer scale and complexity of the events that people will face means that, if it is to be as effective as possible, personal and community capabilities and must be complemented by an effective societal response. A disaster is, by definition, an event whose demands exceed the resources available to respond to them. The effectiveness of the societal response to a disaster is strongly influenced by the ability of those charged with managing and deploying the available resources to optimise the use of these resources. The development of the competencies to do so is the subject of the final paper. Dwyer and Owen discuss how factors such as coordination, communication and organisational flexibility influence adaptive capacity and performance in emergency management operations.

The articles that comprise this special edition suggest that countries and communities that are already linked by geography may also be linked by some commonality in the social and psychological processes that guide how 
their citizens respond to hazardous circumstances. Identification of some cross-cultural equivalence in this regard provides a common basis for collaborative learning and research across national borders (Paton, 2009). This lays the foundation for collaboration among psychologists from around the Pacific Rim on natural hazard issues. Cross-cultural equivalence in processes underlying response to risk also offer risk management agencies in different countries access to a wider range of risk management options. It can also inform the development of intervention strategies for use by humanitarian aid agencies that have to accommodate cultural diversity in their planning. Jang and Wang's paper also underlines the benefits of a more culturally specific approach and highlights the need for more systematic research into how ethnic, cultural and spiritual practices influence natural hazard resilience.

Cross-cultural equivalence was also evident in the finding that community competencies and characteristics derived from mainstream community life influence how people develop their capacity to adapt to and cope with disaster. This supports the argument that the effectiveness of risk-management strategies can be enhanced by integrating them with mainstream community development activities (Anckermann et al., 2005; Paton, 2000; 2008; Paton \& Bishop, 1996; Rich, Edelstein, Hallman, \& Wandersman, 1995). Risk-management strategies that dovetail with community development activities are more likely to be perceived, by community members and civic authorities alike, as offering a solution that has immediate benefits, by facilitating the development of social capital that will show a return on investment in everyday life, and not just in the event of the occurrence of a disaster at some indeterminate time in the future (Paton, 2006b). Participation in identifying shared problems and collaborating with others to develop and implement solutions to resolve them engenders the development of several competencies (e.g., outcome expectancy, collective efficacy) that, in turn, facilitate the development of adaptive capacity and increase the sustainability of societal functioning during a disaster (Paton, 2009).

In conclusion, the articles presented in this special edition suggest that when risk-management strategies accommodate the interdependencies between people, communities and society, estimates of community capability to deal with, adapt to, and develop from exposure to natural disaster will increase substantially. Accommodation of these interdependencies will also increase confidence in the planning and policies that define societal responsibility. This, in turn, increases the likelihood of hazard planning facilitating sustainability in communities whose survival is a function of their capacity to co-exist with the hazardous elements in their environment.

\section{References}

Anckermann, S., Dominguez, M., Sotol, N., Kjaerulf, F., Berliner, P., \& Mikkelsen, E.N. (2005). Psycho-social support to large numbers of traumatized people in postconflict societies: An approach to community development in Guatemala. Journal of Community \& Applied Social Psychology, 15, 136-152.

Joffe, H. (2003). Risk: From perception to social representation. The British Journal of Social Psychology, 42, 55-73.

Paton, D. (2000). Emergency Planning: Integrating community development, community resilience and hazard mitigation. Journal of the American Society of Professional Emergency Managers, 7, 109-118.

Paton, D. (2006a). Disaster resilience: Building capacity to coexist with natural hazards and their consequences. In D. Paton \& D. Johnston (Eds.), Disaster resilience: An integrated approach. Springfield, IL, Charles C. Thomas.

Paton, D. (2006b). Disaster Resilience: Integrating individual, community, institutional and environmental perspectives. In D. Paton \& D. Johnston (Eds.), Disaster resilience: An integrated approach. Springfield, IL, Charles C. Thomas.

Paton, D. (2008). Risk communication and natural hazard mitigation: How trust influences its effectiveness. International Journal of Global Environmental Issues, 8, 2-16.

Paton, D. (2009). Community sustainability and natural hazard resilience: All-hazard and cross-cultural issues in disaster resilience. The International Journal of Environmental, Cultural, Economic \& Social Sustainability, 5, 345-356,

Paton, D., \& Bishop B. (1996). Disasters and communities: Promoting psychosocial well-being. In D. Paton \& N. Long (Eds.), Psychological aspects of disaster: Impact, coping, and intervention. Palmerston North, Dunmore Press.

Rich, R.C., Edelstein, M., Hallman, W.K., \& Wandersman, A.H. (1995). Citizen participation and empowerment: The case of local environmental hazards, American Journal of Community Psychology, 23, 657-677. 